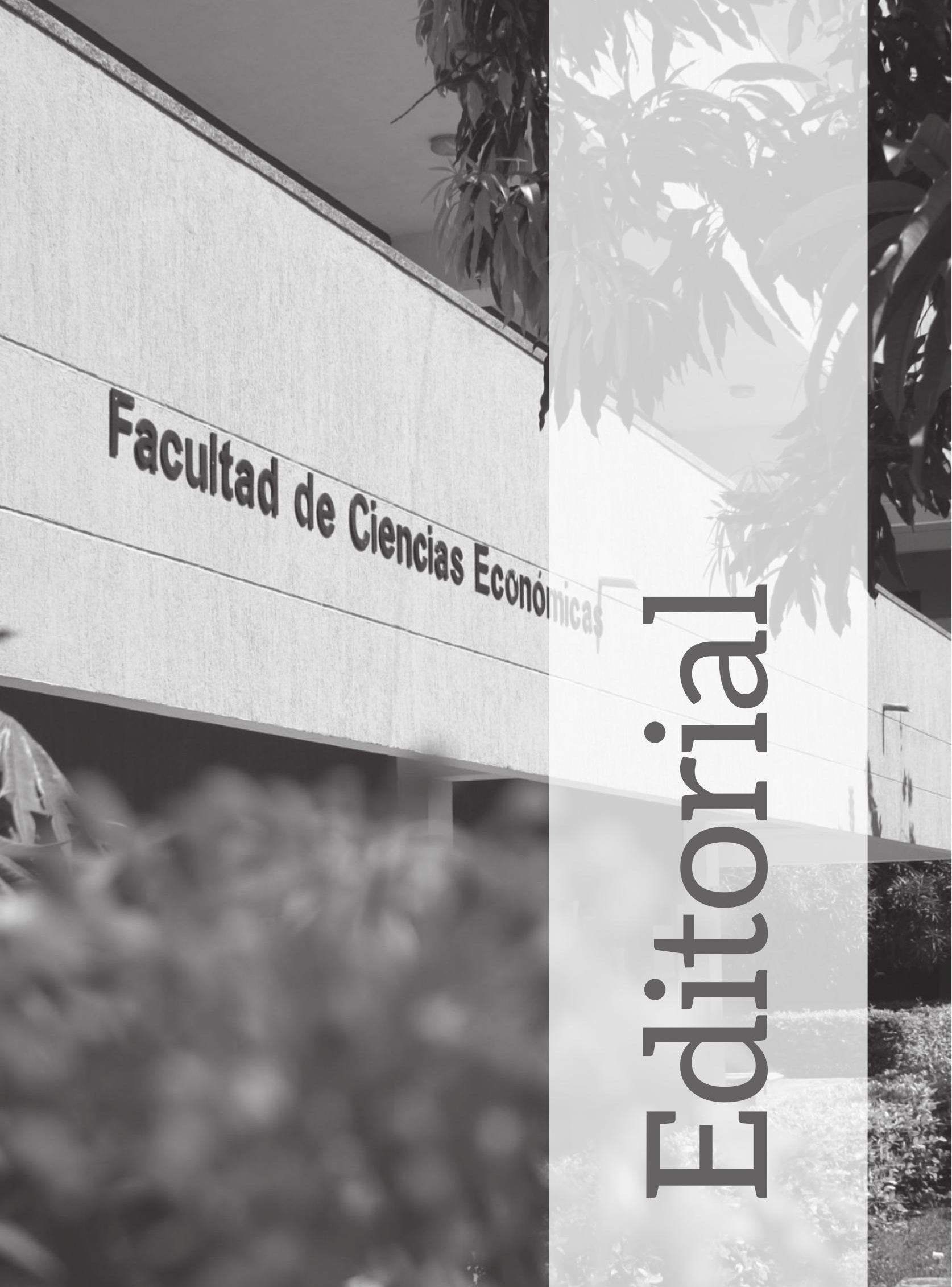





\section{Predatory Journals: Una amenaza real}

Andrés Escobar-Espinoza*

Colombia

Johenis Martínez-Menco**

Colombia

En la última década se ha presentado un fenómeno importante en el mundo de la ciencia que se conoce como predatory publishing el cual se encuentra definido como un modelo de publicación de acceso abierto (Open Access), en el cual los autores deben realizar pagos, pero que no coinciden con el servicio esperado y ofrecido por una revista científica o entidad editora en términos de gestión editorial científica (Beall, 2016; Viniegra, 2012). En este sentido, los manuscritos son publicados sin seguir un procedimiento editorial estándar y sin una revisión o evaluación por pares, que además incluyen condiciones de pago poco claras que anteceden su publicación. De este modo, se desvirtúa el modelo de Acceso Abierto que se financia a través de los denominados Article Processing Charges (APC) que buscan cubrir los costos de la gestión editorial y que se orientan a disponer de manera pública los contenidos publicados, sin la necesidad de suscripciones u otros costos asociados para los potenciales lectores, facilitando así el acceso y la circulación de la ciencia.

El crecimiento del mercado de las publicaciones científicas, ha sido acompañado de un creciente número de revistas científicas de acceso abierto que pueden catalogarse como potenciales, posibles o probables depredadoras (Beall, 2016). Sin embargo, este fenómeno no solamente puede ser atribuible al modelo de Acceso Abierto y puede presentarse en cualquier modelo de negocio presente en el sector debido a las potenciales ganancias (Viniegra, Lisker, Ponce de Leon,1984), y sobre todo por las exigencias actualespara ingresar a la carrera académica (publish or perish) o la consecución de fondos de investigación por parte de los investigadores.

El termino predatory publishing hace referencia a un amplio set de problemas. Por un lado, existe la presencia de actores (revistas o editoriales) en el mercado de publicaciones que emplean homónimos de revistas científicas reconocidas internacionalmente con

\footnotetext{
*Editor de Panorama Económico. Correo de contacto: aescobare@unicartagena.edu.co

** Economista, Universidad de Cartagena. Correo de contacto: jmartinezm5@unicartagena.edu.co
} 
el fin engañar a los investigadores (Butler, 2013), las cuales se podrían categorizar como publicaciones engañosas. Entre otras características comunes de esta categoría, se encuentran: a) nombres engañosos sobre su alcance geográfico, b) indicadores engañosos sobre su impacto científico o sus indexaciones en bases de datos, c) declaraciones engañosas sobre el proceso de revisión o evaluación de manuscritos, d) declaración engañosa sobre la composición de comités editoriales o editores, y e) pagos o servicios adicionales que deben ser cancelados por los autores.

Por otro lado, se pueden además señalar algunos criterios según los cuales una revista podría ser también incluida en la categoría de predatory journal (Delgado \& Corrales, 2017), entre los cuales se tienen: a) Pagos por publicar con ausencia de evaluación por pares, b) notificación de pago tras la aceptación de publicación, c) aceptación y publicación rápida de manuscritos, d) utilización de nombres de científicos reconocidos como parte de sus equipos editoriales, e) falta de claridad sobre la entidad editora y su ubicación geográfica.

Con el de fin de controlar o combatir este fenómeno, en algunas disciplinas como el área de la salud, los editores han planteado una serie de principios de buenas prácticas en la publicación científica (WAME, 2017) y buscan incrementar la transparencia en los procesos y son incluidos dentro de los criterios de evaluación de revistas científicas que emplean organizaciones como COPE, OASP y DOAJ. Recientemente, se ha introducido un énfasis en la responsabilidad que tienen los autores al momento de elegir y evaluar las revistas científicas donde desean publicar sus manuscritos, considerando su integridad, practicas editoriales y reputación científica.

En elámbito latinoamericano y específicamenteel caso colombiano, se conoce poco sobreel impacto de los denominados predatory journals. Colciencias ha introducido recientemente una serie de reformas para evaluar las publicaciones científicas nacionales (Escobar \& López, 2017; Escobar \& Mercado, 2014) en términos de calidad editorial, visibilidad e impacto. Sin embargo, para el caso de las revistas internacionales homologadas en el Índice Bibliográfico Nacional del año 2017, se cuentan con aproximadamente 40.000 revistas científicas, muy por encima de la cantidad de títulos registrados en las bases multidisciplinarias de referencia como Scopus y WoS.

Para resolver esta situación, se requiere una participación activa de los distintos grupos de interés involucrados en los procesos de publicación científica, y desde las diversas disciplinas conocer la experiencia y evolución del fenómeno con el fin de identificar y promover practicas responsables y transparentes.

\section{REFERENCIAS BIBLIOGRÁFICAS}

Beall J. (2016). Medical publishing and the threat of predatory journals. International Journal Women Dermatology, 2: 115-116.

Delgado, P., Corrales, E. (2017). Predatory journals: una amenaza emergente para autores y editors de publicaciones biomedicas. Neurocirugía, 29, 1: 39-43. doi.org/10.1016/j.neucir.2017.07.006 
Butler, D. (2013). Investigating journals: The dark side of publishing. Nature, 495(7442):433-435.

Escobar, A., \& López, N. (2017). Impacto cientifico de la revista Panorama Económico. Panorama Económico, 25 (1), 7-9.

Escobar, A. \& Mercado, M. (2014). The Colombian Scientific Journals and Colciencias' public policy. Panorama Económico, 22, 7-9.

Viniegra L. (2012). Skills to critically read the information, priorities ignored in medical training. Ed Inv Med, 1(4): 199-209

Viniegra VL, Lisker R, Ponce de Leon S (1984). Knowledge on methodology of clinical research in a group of internal medicine residents. Revista de Investigación Clínica, 36:361-4.

WAME (2017). Principles of transparency and best practice in scholarly publishing. Disponible en: http://www.wame.org/about/principles-of-transparencyand-best-practice 


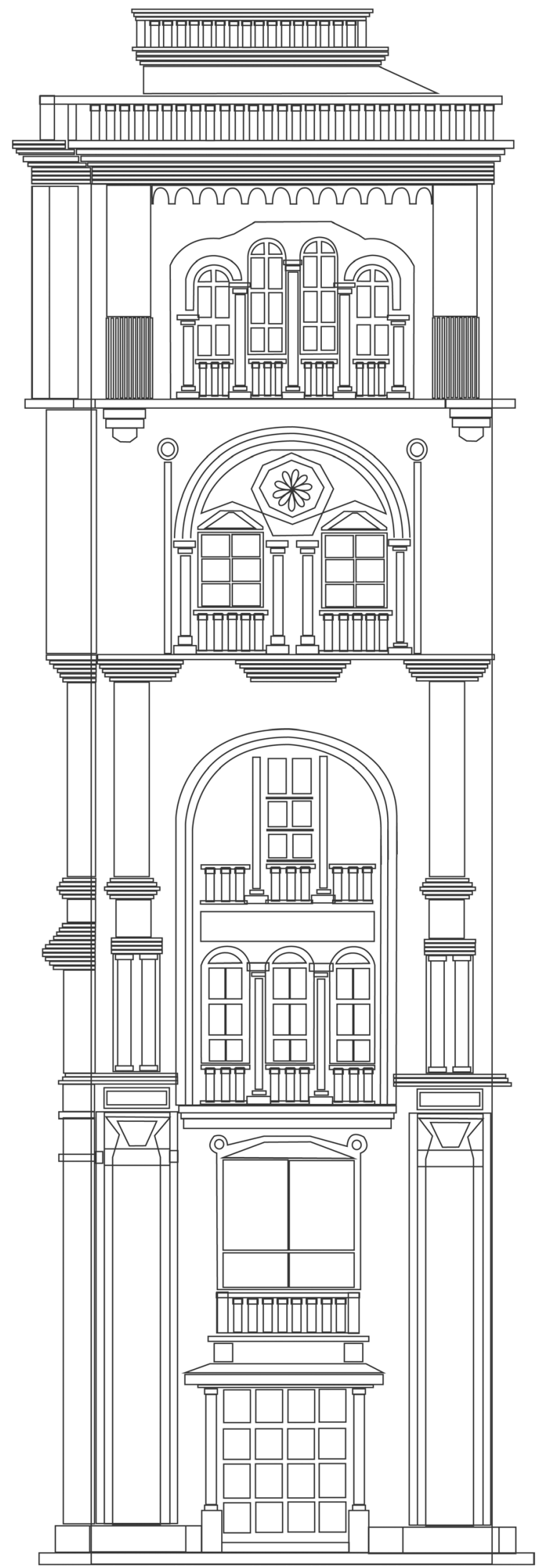

